University of Nebraska - Lincoln

DigitalCommons@University of Nebraska - Lincoln

1998

\title{
Mallard Duckling Growth and Survival in Relation to Aquatic Invertebrates
}

\author{
Robert R. Cox \\ USGS Northern Prairie Wildlife Research Center \\ Mark A. Hanson \\ Wetland Wildlife Populations and Research Group \\ Christianne C. Roy \\ North Dakota State University \\ Ned H. Euliss Jr. \\ USGS Northern Prairie Wildlife Research Center \\ Douglas $\mathrm{H}$. Johnson \\ Northern Prairie Wildlife Research Center, Douglas_H_Johnson@usgs.gov \\ See next page for additional authors
}

Follow this and additional works at: https://digitalcommons.unl.edu/usgsnpwrc

Part of the Other International and Area Studies Commons

Cox, Robert R.; Hanson, Mark A.; Roy, Christianne C.; Euliss, Ned H. Jr.; Johnson, Douglas H.; and Butler, Malcolm G., "Mallard Duckling Growth and Survival in Relation to Aquatic Invertebrates" (1998). USGS Northern Prairie Wildlife Research Center. 224.

https://digitalcommons.unl.edu/usgsnpwrc/224

This Article is brought to you for free and open access by the US Geological Survey at DigitalCommons@University of Nebraska - Lincoln. It has been accepted for inclusion in USGS Northern Prairie Wildlife Research Center by an authorized administrator of DigitalCommons@University of Nebraska - Lincoln. 
Authors

Robert R. Cox, Mark A. Hanson, Christianne C. Roy, Ned H. Euliss Jr., Douglas H. Johnson, and Malcolm G. Butler 


\title{
MALLARD DUCKLING GROWTH AND SURVIVAL IN RELATION TO AQUATIC INVERTEBRATES
}

\author{
ROBERT R. COX, JR.,' U.S. Geological Survey, Biological Resources Division, Northern Prairie Wildlife Research Center, 8711 \\ 37th Street SE, Jamestown, ND 58401, USA \\ MARK A. HANSON, Minnesota Department of Natural Resources, Wetland Wildlife Populations and Research Group, Bemidji, \\ MN 56601, USA \\ CHRISTIANNE C. ROY, 2 Department of Zoology, North Dakota State University, Fargo, ND 58105, USA \\ NED H. EULISS, JR., U.S. Geological Survey, Biological Resources Division, Northern Prairie Wildife Research Center, 8711 \\ 37th Street SE, Jamestown, ND 58401, USA \\ DOUGLAS H. JOHNSON, U.S. Geological Survey, Biological Resources Division, Northern Prairie Wildlife Research Center \\ 8711 37th Street SE, Jamestown, ND 58401, USA
}

MALCOLM G. BUTLER, Department of Zoology, North Dakota State University, Fargo, ND 58105, USA

\begin{abstract}
Identification and assessment of the relative importance of factors affecting duckling growth and survival are essential for effective management of mallards on breeding areas. For each of 3 years (1993-95), we placed $\mathrm{F}_{1}$-generation wild mallard (Anas platyrhynchos) females on experimental wetlands and allowed them to mate, nest, and rear broods for 17 days. We manipulated invertebrate densities by introducing fathead minnows (Pimephales promelas) at high densities in half of the wetlands on which broods were confined. Day17 body mass of surviving ducklings $(n=183)$ was greater for ducklings that were heavier at hatch; the difference averaged $1.7 \mathrm{~g}$ at day 17 for each $1.0 \mathrm{~g}$ at hatch $(P=0.047)$. Growth ratio (the proportion of body mass attained by ducklings when they were last measured relative to that predicted for wild female mallard ducklings) also was positively related to body mass at hatch $(P=0.004)$. Mean day-17 body mass and mean growth ratio of ducklings per brood (each adjusted for body mass at hatch) were positively related to numbers of aquatic invertebrates $(P s<0.001)$ and negatively related to variance in the daily minimum air temperature during the exposure period $(P s<0.020)$. Early growth of mallards was more sensitive to variation in numbers of invertebrates than to air temperature or biomass of invertebrates. Duckling survival was positively related to growth ratio $(P<0.001)$. Our study provides parameter estimates that are essential for modeling growth and survival of mallard ducklings. We emphasize the need for conserving brood-rearing wetlands in the Prairie Pothole Region that are capable of supporting high densities of aquatic invertebrates.
\end{abstract}

JOURNAL OF WILDLIFE MANAGEMENT 62(1):124-133

Key words: air temperature, Anas platyrhynchos, aquatic invertebrates, brood, duckling, early development, growth, mallard, nutrition, survival.

The early developmental phase is among the most important yet least studied periods in the life cycle of waterfowl (Sedinger 1992). For mallards and many other species of ducks, diets during the first 2 weeks of this period consist almost entirely of aquatic invertebrates (Chura 1961, Perret 1962, Sugden 1973). Thereafter, mallard ducklings consume progressively greater amounts of plant matter prior to fledging (Chura 1961, Street 1977). Hence, although it is widely accepted that early growth of ducklings is positively related to abundance of aquatic macroinvertebrates, efforts to quantify this relation in natural or seminatural settings have been hampered by lack of control over factors

\footnotetext{
${ }^{1}$ E-mail: robert_cox@usgs.gov

2 Present address: Kansas Department of Wildlife and Parks, Box 1525, Emporia, KS 66801, USA.
}

influencing duckling growth (see review in Sedinger 1992).

In addition to duckling growth, prefledging survival is among the least understood components of recruitment in mallards (Cowardin et al. 1985). Most mortality of mallard ducklings occurs during the first 2 weeks of life (Orthmeyer and Ball 1990, Rotella and Ratti 1992). Predation often is identified as an important source of duckling mortality (Talent et al. 1983), but abiotic factors, primarily weather, may directly influence duckling survival (e.g., Korschgen et al. 1996). Adverse weather also can indirectly influence growth and survivorship of ducklings by altering time-activity budgets (increased time spent being brooded vs. foraging) or by decreasing the availability of aquatic invertebrates (reviewed by Johnson et al. 1992). Ducklings with more rapid early growth should be less susceptible to weather-related sources of 
mortality because of larger body size (i.e., decreased surface area:volume ratio) and greater nutrient reserves (Sedinger 1992). Thus, early growth of ducklings may serve as an important link between availability of food resources and survival. In turn, brood and duckling survival are among the most important factors affecting production and the subsequent population dynamics of mallards (Johnson et al. 1992).

We measured growth and survival of captive mallard ducklings during their critical early developmental period. We tested for variation in duckling growth in relation to (1) body mass at hatch, (2) numbers and biomass of aquatic invertebrates, and (3) several measures of ambient air temperature. Finally, we tested for variation in duckling survival in relation to growth. Our objective was to develop predictive equations for these relations.

\section{STUDY AREA}

We conducted our study using a complex of 20 experimental wetlands (hereafter, wetlands) constructed in 1992 at Northern Prairie Wildlife Research Center, $3 \mathrm{~km}$ east of Jamestown, North Dakota $\left(46^{\circ} 53^{\prime} \mathrm{N}, 98^{\circ} 38^{\prime} \mathrm{W}\right)$. The flooded surface of each wetland was $22 \times 22 \mathrm{~m}$, and basins were sloped at $14^{\circ}$ to form a $12-\times 12$ $\mathrm{m}$ area in the center of each wetland, which was flooded to maximum depth of $1.2 \mathrm{~m}$. To prevent seepage, we installed waterproof liners in each wetland and then overlaid them with sediments. We spaced wetlands evenly in a $4 \times 5$ array, and each wetland was enclosed by steel chain link fencing and covered with nylon netting. This construction excluded predators and isolated females and their ducklings from other such groups. Predominant emergent hydrophytes were a mix of wet-meadow, shallowmarsh, and deep-marsh species (Stewart and Kantrud 1971) that included Hordeum, Phalaris, Poa, Polygonum, and Typha spp. Enclosures included strips of upland (approx $7 \mathrm{~m}$ width) surrounding each wetland.

\section{METHODS}

We initially flooded wetlands during August 1992. In spring 1993, we inoculated wetlands with water, benthic core samples, and dry shoreline sediments from natural wetlands to speed colonization of plankton and aquatic macroinvertebrates (Euliss and Grodhaus 1987). In late April 1993, we fertilized each wetland with alfalfa pellets $(25 \mathrm{~kg})$ to enhance initial in- vertebrate populations. Thereafter, we managed water levels to simulate natural water regimes of semipermanent wetlands (Stewart and Kantrud 1971). We drained wetlands to a depth of $0.5 \mathrm{~m}$ by September of each year and then used well water to reflood them to capacity $(1.2 \mathrm{~m})$ in April or early May.

We added fathead minnows, important predators of aquatic insects and crustaceans in prairie wetlands (Held and Peterka 1974, Hanson and Riggs 1995), to half of our wetlands to establish a wide range of invertebrate densities and to satisfy objectives of other concurrent studies (see Hanson et al. 1995, Roy 1995). Each year during 1993-95, we randomly selected wetlands to receive 1 of 4 treatments: (1) fathead minnows only, (2) mallard brood only, (3) fathead minnows and mallard brood, and (4) neither (control). Here, we present results from treatments with broods (2 and 3 ). We stocked wetlands selected to receive minnows with 10,000 adult fathead minnows ( $50 \mathrm{~g} ; 35-55 \mathrm{~mm}$ total length) in mid-late May each year.

In late April or early May, we placed a pair of $F_{1}$-generation wild mallards on each wetland selected to receive a mallard brood. Female mallards in 1993 and 1994 were from the same cohort and were yearlings in 1993. Females in 1995 were from other cohorts and were $\geq 2$ years of age. No individual female was used in $>1$ year of the study. We removed males from wetlands at the onset of incubation. We provided a high-protein commercial diet ad libitum to pairs and incubating females. Commercial food was removed before ducklings hatched; thereafter, females and broods foraged only on natural foods.

To minimize temporal variation in factors influencing duckling growth and survival, we synchronized hatching within 5 days each year by replacing eggs from early-laid clutches with eggs from $F_{1}$-generation wild mallards of known incubation stage. We standardized clutch size to 10 for each female. We webtagged and determined body mass (spring scales; $\pm 0.5 \mathrm{~g}$ ) of ducklings on the day they were hatched but were dry and still in the nest (day 1 of the experiment). We visually verified brood sizes at least once daily, searched for any missing ducklings, and determined their mass if recovered dead. On day 17, we used sliding-door traps to capture surviving ducklings as broods, euthanized them immediately with an intrapleuritoneal injection of $1 \mathrm{~mL}$ of sodium pentobarbital, 
and redetermined their mass. Techniques for care and handling of adult mallards and ducklings were approved by the Animal Care and Use Committee of Northern Prairie Wildlife Research Center and conform to standards of the Animal Welfare Act (Public Law 990198 and 9 CFR Parts 1, 2, and 3).

We indexed aquatic invertebrate abundance with activity traps, which provide estimates similar to those obtained by more active sampling methods (Brinkman and Duffy 1996). We used 2 types of traps simultaneously in each wetland to reduce potential trap bias and to sample more thoroughly the water-surface zone where most ducklings feed (Sugden 1973). We distributed 10 activity traps (modified from Swanson 1978) throughout the water column in each wetland by suspending them horizontally from PVC frames at approximately $0.3-\mathrm{m}$ intervals from immediately below the water surface to $0.9 \mathrm{~m}$ ( 1 trap at the $0.3-\mathrm{m}$ contour, 2 traps at the $0.6-\mathrm{m}$ contour, etc.). We also deployed 4 stratified activity traps in each wetland, suspending 1 trap from each PVC frame. Each stratified trap was composed of 3 layered compartments that collected invertebrates from discrete water-column layers spaced approximately $5 \mathrm{~cm}$ above to $15 \mathrm{~cm}$ below the water surface; thus, a single sampling of each wetland consisted of 22 samples. To exclude minnows, we covered apertures of activity traps with $1.2 \mathrm{~cm} \mathrm{di-}$ ameter screen. To minimize disturbance to broods, we sampled invertebrates only once yearly while broods were present, and on about day 8 of the experiment (Fig. 1). We removed activity traps from wetlands about $24 \mathrm{hr}$ after deployment and preserved invertebrates in $80 \%$ ethanol. We estimated aquatic invertebrate numbers in each wetland by counting and identifying invertebrates from samples by taxon and then calculating the mean number of organisms per trap for both types of activity traps. To estimate invertebrate biomass, we dried them to constant mass at $60^{\circ} \mathrm{C}$ prior to determining mass $( \pm 0.0001 \mathrm{~g})$. Further details of our invertebrate sampling methods are described by Hanson et al. (1995) and Roy (1995).

For analysis, we considered 2 response variables as measures of duckling growth: (1) body mass at 17 days (for surviving ducklings only), and (2) growth ratio (for all ducklings). We define growth ratio as the proportion of "expected" body mass achieved by a duckling when last measured. To estimate expected body mass, we

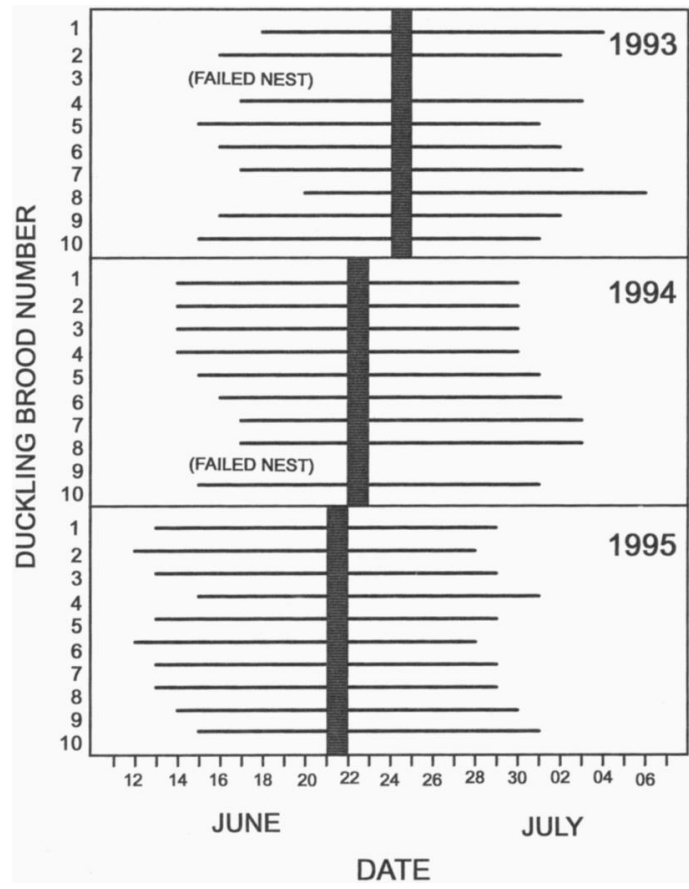

Fig. 1. Dates of exposure for mallard broods reared on experimental wetlands in North Dakota for each year. Vertical bars indicate dates on which invertebrates were sampled.

used PROC NLIN (SAS Institute 1990) to fit a 4-parameter growth curve modified from Richards' (1959) growth function (Sugden et al. 1981) to body mass data from wild female mallard ducklings summarized in Lokemoen et al. (1990). The growth curve was of the following form:

$\hat{W}(t)=W_{\infty}\left[1-(1-m) e^{\left[-k\left(t-t_{0}\right) / m^{m /(1-m)}\right]}\right]^{1 /(1-m)}$,

where $\hat{W}(t)$ is the estimated body mass at age $t, W_{\infty}$ is the asymptotic mass, $m$ is the shape parameter, $k$ is the maximum relative growth rate (per day), and $t_{0}$ is the age in days at maximum rate of growth. To produce realistic growth curves, we constrained $W_{\infty}$ to be $\leq$ $1048.74 \mathrm{~g}$ (Bellrose 1976) and $m$ to be $>1.01$ (Sugden et al. 1981). It was necessary to refit growth curves because those presented in Lokemoen et al. (1990) lacked a shape parameter and consequently produced a symmetric (i.e., logistic) curve that overestimated duckling body mass at early stages of development. We chose wild female mallard ducklings because this growth curve fit our data more closely than the growth curve for males, and more closely than those fit to captive mallards (Sugden et al. 1981, 
Rhymer 1982). Parameter estimates from our final fitted equation were $W_{\infty}=1048.74, m=$ 1.3305, $k=0.0185$, and $t_{0}=31.99$. We then calculated a growth ratio for each duckling as follows:

$$
\text { Growth ratio }=\frac{W(t)_{\text {OBSERVED }}}{\hat{W}(t)_{\text {EXPECTED }}},
$$

where $t$ is the age of the duckling when we last determined its mass.

We first tested for a relation between each response variable (day-17 body mass for surviving ducklings and growth ratio for all ducklings) and body mass at hatch using least-squares regression (PROC GLM; SAS Institute 1990). If this relation was significant $(P<0.05)$, we then adjusted the response variable for each duckling for its body mass at hatch by adding the residual from the regression for that duckling to the overall mean of the response variable (Ankney and Afton 1988, Afton and Ankney 1991). To control for any potential lack of independence among brood mates, we next averaged the adjusted response variables over ducklings in each brood. We then used multiple regression (PROC GLM; SAS Institute 1990) to assess relations of the 2 adjusted response variables (averaged over ducklings within a brood) to (1) mean density of aquatic invertebrates (numbers and biomass) in each wetland each year; and (2) 3 measures of minimum air temperature during the exposure period, including (a) the mean daily minimum temperature, (b) the number of days with daily minimum temperature below $10^{\circ} \mathrm{C}$, and $(\mathrm{c})$ the variance in the daily minimum temperature. We obtained daily temperature data recorded at the Jamestown Airport from the National Oceanic and Atmospheric Administration. Thus, we fitted 6 models for each response variable, 1 for each combination of 2 measures of invertebrate density and 3 measures of air temperature. We included the interaction in initial models and used backward stepwise procedures to eliminate nonsignificant $(P>0.05)$ terms, beginning with interactions. We used standardized regression coefficients (PROC REG; SAS Institute 1990) to examine the relative influence of terms included in our final fitted models. We did not include year as an explanatory variable in our models because our goal was to develop predictive equations applicable to years outside of those in our study. However, we tested for year effects potentially caused by factors not included in our models by testing whether residuals from our final fitted models differed among years (PROC GLM; SAS Institute 1990). In all equations in this paper, body mass is expressed in grams and temperature is expressed in degrees Celsius.

We modeled 17-day survival of ducklings as a dichotomous response to their growth ratios. Survivorship of ducklings in the same brood may not be independent (i.e., the intrabrood correlation may differ from zero). To account for the possibility of dependence within broods, we used a first-order Taylor series approximation and a between-brood variance estimation procedure to obtain consistent logistic regression estimators (Bieler and Williams 1995). We fitted the model assuming that survival probabilities of ducklings within the same brood were dependent (SUDAAN, PROC LOGISTIC; Shah et al. 1996) and independent (PROC LOGISTIC; SAS Institute 1990, 1996). We assessed fit of models using goodness-of-fit tests (Hosmer and Lemeshow 1989, SAS Institute 1996). To examine the relation between survival and age of ducklings, we used PROC LIFETEST (SAS Institute 1990) to estimate KaplanMeier (1958) survival rates and associated 95\% confidence limits of ducklings during the 17-day interval.

Two females (1 each in 1993 and 1994) failed to hatch broods. We also could not measure body mass of 5 ducklings that disappeared (and we presumed died) during the experiment, and we were unable to assign final body mass for 4 ducklings that lost web tags. We excluded these 9 ducklings from analyses of growth and survival but included them in our estimation of KaplanMeier survival rates. Five ducklings from each brood in 1993 were color-marked to obtain behavioral data for another study. Because growth and survival of these ducklings appeared adversely affected by markers (J. E. Austin, Northern Prairie Wildlife Research Center, personal communication), we excluded these ducklings from all analyses.

\section{RESULTS \\ Day-17 Body Mass}

Day-17 body mass of surviving ducklings was positively related $\left(F_{1,181}=3.99, P=0.047\right)$ to, but poorly predicted by, body mass at hatch. Our final equation was as follows: day-17 body mass $=62.3+1.7$ (body mass at hatch); $r^{2}=$ 0.02 . Thus, day- 17 body mass was greater for 
ducklings that were heavier at hatch; the difference averaged $1.7 \mathrm{~g}$ at day 17 for each $1.0 \mathrm{~g}$ at hatch. Mean day-17 body mass of ducklings per brood (adjusted for body mass at hatch) was positively related $\left(F_{1,25}=14.58, P<0.001\right)$ to invertebrate numbers (range in mean number of invertebrates per trap among wetlands $=17$ $257)$ and negatively related $\left(F_{1,25}=5.85, P=\right.$ $0.02)$ to variance in daily minimum air temperature $\left(\right.$ range $=3.4-15.4^{\circ} \mathrm{C}$ ). The interaction between invertebrate numbers and variance in the daily minimum air temperature was not significant $\left(F_{1,24}=0.13, P=0.73\right)$. Our final fitted equation was as follows: mean day-17 body mass of ducklings per brood $=128.04+0.29$ (mean number of invertebrates per activity trap) 3.53 (variance in daily minimum temperature); $R^{2}=0.52$. Thus, mean day- 17 body mass of ducklings per brood (adjusted for body mass at hatch) increased $0.29 \mathrm{~g}$ for each unit increase in mean number of aquatic invertebrates captured per trap and decreased $3.53 \mathrm{~g}$ with each unit increase in variance in daily minimum air temperature during the exposure period. Standardized regression coefficients were 0.55 for number of aquatic invertebrates and -0.35 for variance in daily minimum air temperature, indicating that day- 17 body mass of ducklings per brood (adjusted for body mass at hatch) was more sensitive to invertebrate numbers than to variance in daily minimum air temperature. Using residuals from our final fitted model, we found no evidence $\left(F_{2,25}=0.42, P=0.66\right)$ that mean day-17 body mass of ducklings per brood (adjusted for body mass at hatch) differed in relation to year, after we controlled for variation from invertebrate numbers and variance in daily minimum air temperature. Relations with alternative measures of invertebrate density (biomass of aquatic invertebrates per trap, range $=$ 0.004-0.147 g), air temperature (mean daily minimum, range $=11.2-16.6^{\circ} \mathrm{C}$; number of days $<10^{\circ} \mathrm{C}$, range $=0-6$ days $)$, and other interactions were not significant $(P \mathrm{~s}>0.17)$.

\section{Growth Ratio}

Growth ratio for each duckling was positively related $\left(F_{1,212}=8.31, P=0.004\right)$ to, but poorly predicted by, body mass at hatch. Our final fitted equation was as follows: growth ratio = $0.177+0.013$ (body mass at hatch); $r^{2}=0.04$. Mean growth ratio of ducklings per brood (adjusted for body mass at hatch) was positively related $\left(F_{1,25}=14.38, P<0.001\right)$ to inverte-

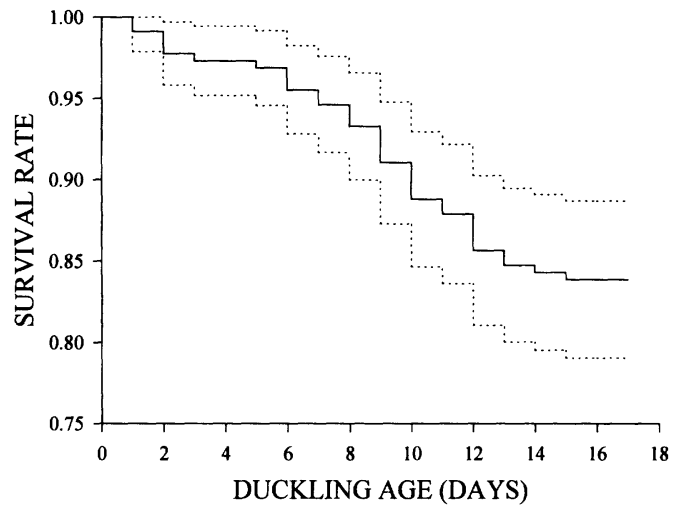

Fig. 2. Kaplan-Meier survival function (solid line) and $95 \%$ confidence limits (dotted lines) for mallard ducklings $(n=223)$ reared on experimental wetlands in North Dakota, 1993-95.

brate numbers and negatively related $\left(F_{1,25}=\right.$ $7.30, P=0.01)$ to variation in daily minimum air temperature. The interaction between invertebrate numbers and variation in daily minimum air temperature was not significant $\left(\boldsymbol{F}_{1,24}\right.$ $=0.01, P=0.93$ ). Our final fitted equation was as follows: mean growth ratio of ducklings per brood $=0.716+0.002$ (mean number of invertebrates per trap) -0.022 (variance in daily minimum temperature); $R^{2}=0.54$. Standardized regression coefficients were 0.53 for numbers of invertebrates and -0.38 for variance in daily minimum air temperature, indicating that mean growth ratio of ducklings per brood was more sensitive to invertebrate numbers than to variance in daily minimum air temperature. Using residuals from our final fitted model, we found that mean growth ratio of ducklings per brood (adjusted for body mass at hatch) did not $\operatorname{differ}\left(F_{2,25}=0.27, P=0.76\right)$ in relation to year, after we controlled for variation from invertebrate numbers and variance in daily minimum air temperature. Other measures of invertebrate density (biomass), air temperature (mean daily minimum and number of days below $10^{\circ}$ C), and other interactions were not related to growth ratio $(P s>0.35)$.

\section{Survival}

The 17-day survival rate for 223 ducklings we monitored was 0.84 ( $\mathrm{SE}=0.025 ; \mathrm{Fig}$. 2). There was no incidence of total brood loss. We determined final body mass for 31 of 36 ducklings that died during the 17-day experiment.

Duckling survival was positively related to growth ratio in our analysis that accounted for potential intrabrood correlation among duck- 
lings (Wald $\left.\chi^{2}{ }_{1}=11.37, P=0.0007\right)$ and in our analysis that treated ducklings in the same brood as if they were independent (Wald $\chi^{2}{ }_{1}=$ 25.54, $P<0.0001$ ). However, these models did not fit the observed data well (Hosmer and Lemeshow goodness-of-fit statistic $=41.55,8 \mathrm{df}$, $P<0.0001$ ), primarily because observed growth ratios of ducklings that died early (in the first 3 days of life) were much higher than predicted by our logistic regression model (Fig. 3). Therefore, we repeated our analysis and excluded the 4 ducklings that died within 3 days posthatch (see explanation in Discussion). We again found that survival was positively related to growth ratio in analyses that controlled for potential intrabrood correlation (Wald $\chi^{2}{ }_{1}=31.40, P<$ 0.001 ) and in analyses that treated ducklings as independent (Wald $\chi^{2}{ }_{1}=26.29, P<0.001$ ). Intrabrood correlation in survival was 0.029 , a value sufficiently close to zero to justify treating fates of ducklings in the same brood as independent. These models fit our data (Hosmer and Lemeshow goodness-of-fit statistic $=7.25$, $7 \mathrm{df}, P=0.40)$. Our final fitted equation was

$$
P(\text { Surv })=\frac{e^{-6.6983+18.3853(\text { Growth ratio) }}}{1+e^{-6.6983+18.3853(\text { Growth ratio) }}}
$$

where $P($ Surv $)$ is the probability that a mallard duckling will survive the entire period from 3 to 17 days of age (Fig. 3).

\section{DISCUSSION}

\section{Duckling Growth}

Most earlier studies of relations between nutrition and growth of ducklings in natural or seminatural settings were anecdotal or characterized by small sample sizes, lack of replication, or other difficulties associated with controlling and measuring important variables under field conditions. Thus, although previous studies were important for generating, and in some cases testing, hypotheses about nutritional effects on growth, they have not allowed for the estimation of parameters relating invertebrate density to growth. Our finding that duckling growth was positively related to invertebrate density is consistent with results of previous research. For example, Street (1978) reported higher growth rates for mallard ducklings fed greater amounts of insect larvae, and Hunter et al. (1984) reported that ducklings from a mixed brood of mallards and American black ducks (Anas rubripes) on a pesticide-treated wetland

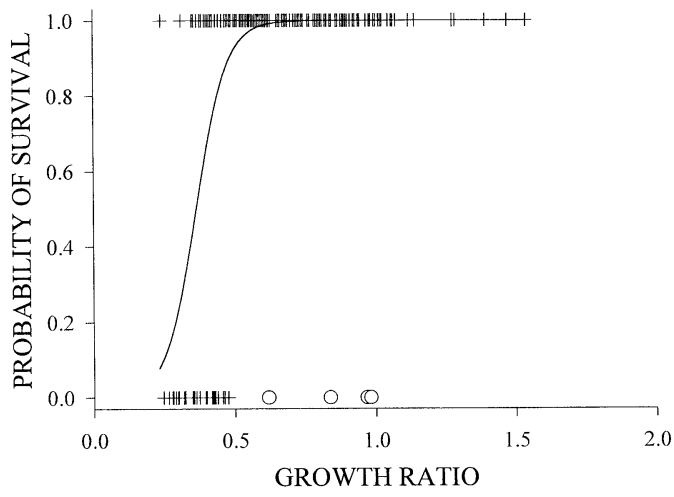

Fig. 3. Probability of survival for mallard ducklings from 3 through 17 days of age ( $\mathrm{Y}$-axis) reared on experimental wetlands in North Dakota, 1993-95, in relation to growth ratio (Xaxis). Actual growth ratios of ducklings that lived (probability of survival $=1$ ) and died (probability of survival $=0$ ) during the experiment are denoted by symbols (plus signs or open circles). Ducklings that died when they were $\leq 3$ days of age (open circles) were excluded from analysis. Solid line denotes probability function from logistic regression.

grew slower than those in a similar brood on an unsprayed wetland. Pehrsson and Nyström (1988) suggested that low growth rates of oldsquaw (Clangula hyemalis) ducklings were associated with high intraspecific competition for fairy shrimp (Polyartemia forcipata). McCarthy (1995) attributed low growth and survival rates of mallard ducklings on pesticide-treated wetlands to chronic effects of decreased invertebrate abundance. Other authors have attempted to relate invertebrate density directly to duckling survival. For example, Bengtson (1972) attributed high duckling mortality in 1 year of a long-term study to a shortage of midges (Chironomidae), and Hill et al. (1987) reported that mallard ducklings feeding in lakes with high densities of fish (and low densities of aquatic invertebrates) survived at lower rates than those feeding in riverine habitats with low densities of fish. Brood sizes of tufted ducks (Aythya fuligula) appeared to increase following removal of fish from wetlands where ducklings were foraging (Giles 1994).

Our analyses indicated that mallard duckling growth was greater as numbers, but not biomass, of invertebrates increased. Large differences in numbers of invertebrates among wetlands mainly reflected variation in small but numerous taxa such as water fleas (Cladocera), copepods (Copepoda), and seed shrimp (Ostracoda) (Roy 1995). Large differences in biomass among wetlands mainly reflected variation in relatively heavy food items, particularly snails 


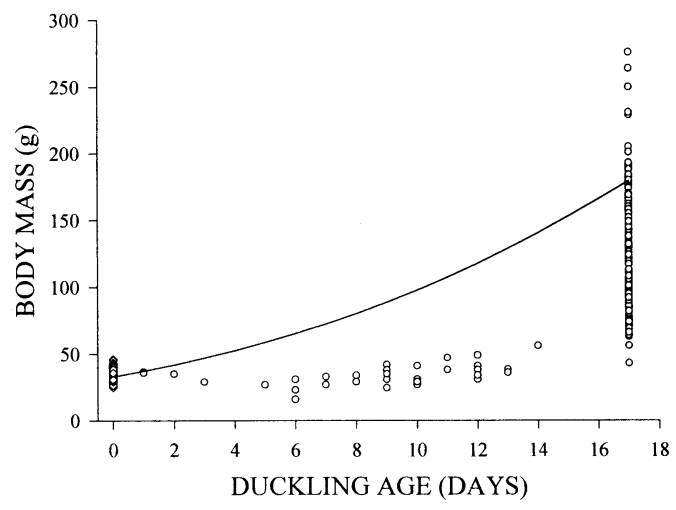

Fig. 4. Body mass at hatch (diamonds), on the day of death (circles plotted on days 1-14), and at the end of the experiment (circles plotted on day 17) for mallard ducklings reared on experimental wetlands in North Dakota, 1993-95. The curved line is the growth curve fitted to wild mallard ducklings (Lokemoen et al. 1990) with 4-parameter Richards' (1959) curve modified by Sugden et al. (1981). Note that body masses of ducklings that died on days 1-3 are closer to the fitted growth curve than those of ducklings that died later in the experiment.

(Gastropoda; M. A. Hanson, unpublished data). Our finding that number of invertebrates was a better predictor of duckling growth than invertebrate biomass suggests that ducklings did not assess the relative value of food items and foraged primarily on foods that were most numerous. The benthic habits and large size of many snails in our wetlands may have decreased attractiveness of these food items to ducklings in our study. However, foraging inefficiency of newly hatched ducklings, differential capture rates among various invertebrate taxa by our activity traps, or temporal variation in invertebrate biomass that we failed to measure by sampling invertebrates on a single day also may have limited our ability to detect biomass effects.

Few ducklings in our experiment grew as rapidly as wild mallard ducklings on which our growth curve was based (Fig. 4). The mean growth ratio of surviving ducklings was 0.69 and the median was 0.65 , which contrasts to a ratio of 1.0, had surviving ducklings gained body mass at the same rate as wild mallard ducklings. Reduced growth is expected given that we stocked half the study wetlands with high densities of fathead minnows, which are known to suppress aquatic invertebrate populations (Hanson and Riggs 1995). Confinement of ducklings to a single wetland also created an unnatural situation because females could not move broods to better foraging sites, as they might in the wild. Therefore, we believe that our exper- iment represents a "worst-case" scenario, but one that might simulate a situation in which large-scale treatments such as pesticide applications or fish introductions dramatically reduce invertebrate populations in wetlands over a brood's entire range.

Effects of Air Temperature.-We found that variance in the daily minimum air temperature was a significant predictor of growth in mallard ducklings, but that mean daily minimum air temperature and number of days $<10^{\circ} \mathrm{C}$ were not. The mean daily minimum air temperature for broods ranged from 11.2 to $16.6^{\circ} \mathrm{C}$. The number of brood exposure days with minimum air temperatures $<10^{\circ} \mathrm{C}$ was $\leq 2$ during 1994 and 1995, and ranged from 4 to 6 during 1993. Although temperature effects on ducklings are not well understood, our failure to detect relations between growth and mean daily minimum air temperature or number of days $<10^{\circ} \mathrm{C}$ may indicate that limiting temperature thresholds were never reached.

Variable minimum temperatures may have disrupted invertebrate activity rhythms, and spatial or temporal variation in the location of invertebrates between warm and cold conditions may have prevented ducklings from locating and using them as a dependable food supply. For example, midges probably are most available to feeding waterfowl as they emerge on the surface of open water when conditions are warm and calm. However, adult midges become inactive when air temperatures are $<8$ $11^{\circ} \mathrm{C}$ (Gibson 1945, Syrjämäki 1964). Consequently, midges are most available as adults in emergent vegetation when conditions are cool and windy (Swanson and Sargeant 1972, Danell and Sjöberg 1982). Diel emergence patterns of midges, other dipterans, and dragonflies (Odonata) also may differ markedly in relation to air and water temperatures (Williams 1961, Swanson and Sargeant 1972, Trottier 1973, Kureck 1979). Swanson (1977) reported that water fleas were highly available to feeding waterfowl only on warm summer nights when low oxygen conditions forced them to the water surface. Therefore, when daily minimum air temperatures are highly variable, daily availability of invertebrate foods may fluctuate greatly and contribute to poor growth of ducklings.

\section{Duckling Survival}

We found that survival of mallard ducklings was positively related to growth (as measured 
by growth ratio), which is consistent with suggestions from previous research. Street (1977) suggested that rapidly growing ducklings with diets high in invertebrates could withstand unfavorable weather much better than those growing more slowly. Brown and Hunter (1984/85) used growth rates reported for a single mixed brood of mallards and American black ducks and estimated that a $37 \%$ decrease in growth rate of mallard ducklings (causing the typical day-14 body mass to be attained on day 19) would increase their mortality rate in the first 2 weeks from 39 to $54 \%$. Survival of mallard ducklings in our study was particularly sensitive to growth ratios $<0.6$. However, our ducklings were not exposed to predation. If predators such as mink (Mustela vison) and gulls (Larus spp.) selectively prey on the most vulnerable ducklings (Sargeant et al. 1973, Swennen 1989), then a positive relation between growth and survival may be sustained or even enhanced in wild situations where predation is an important source of mortality.

Our model relating duckling survival to growth ratio did not fit our data when we included ducklings that were $\leq 3$ days of age, suggesting that duckling mortality in the first 3 days was not related to growth. Food resources may not be critical to ducklings immediately after hatch because they can use lipids in residual yolk and body tissues through 4 days of age (Sedinger 1992). Ducklings also can survive for several days without food (Kear 1965, Krapu 1974, Duncan 1988, Sedinger 1992). For example, northern pintail (Anas acuta) ducklings deprived of food for $72 \mathrm{hr}$ lost only $3.7 \mathrm{~g}$ (12.5\%) of body mass (Duncan 1988). Mean daily increase in body mass (i.e., growth rate) of mallard ducklings is low during the first days of life but increases each day until the point of maximum growth rate is reached at 17-26 days of age for captive mallards (Sugden et al. 1981, Rhymer 1982), or 32-38 days for wild mallards (Lokemoen et al. 1990, and refitting our 4-parameter growth curve to their data). Thus, it is not surprising that growth ratios of ducklings that died early in our experiment were high. Lack of model fit caused by our including in analyses ducklings that died early in our experiment may indicate that growth is an important predictor of survival only after ducklings are $\geq 3$ days old, at least in the absence of predation.

\section{MANAGEMENT IMPLICATIONS}

Our study provides parameter estimates for associations among invertebrate densities and other factors related to duckling growth and survival that are essential for modeling recruitment rates of mallards. We plan to incorporate predictive equations developed in this study into the mallard productivity model (Johnson et al. 1987) to increase its accuracy in predicting recruitment. We emphasize that our parameter estimates should not be extended beyond the range of explanatory variables recorded in our study because these relations may become asymptotic as invertebrates, for example, become numerous beyond the point where maximum growth of ducklings is reached, or as invertebrates become limited beyond the point at which ducklings cannot maintain body mass Data from activity traps are easily obtained, and thus might serve as a convenient tool for wetland managers in need of methods that allow rapid assessment of wetland habitat suitability for ducklings. Sampling effort (in time or space) should be increased in correspondence to variability of invertebrate numbers.

Our study supports earlier recommendations that wetlands containing high densities of invertebrates should be conserved throughout the Prairie Pothole Region and in other areas of waterfowl production. Seasonal wetlands in the Prairie Pothole Region should receive particular attention because these wetlands are (1) highly productive (Swanson and Duebbert 1989), (2) used as brood-rearing habitats during wet years (Talent et al. 1982), and (3) more susceptible to drainage than more permanent wetlands. Our results indicate that growth and survival of mallard ducklings, and probably other species of juvenile ducks, could be reduced if activities such as chemical application, fish introduction, and tillage or drainage of wetland basins decrease invertebrate abundance over large areas.

\section{ACKNOWLEDGMENTS}

We thank G. A. Swanson for encouragement and advice on numerous aspects of our study, D. A. Wrubleski for discussion and literature on weather-related variation in aquatic invertebrate activity rhythms, and M. R. Riggs for help with the logistic regression analysis. J. T. Lokemoen provided access to data on body mass of wild mallard ducklings. M. L. Holt, F. J. Ossman, G. and B. Reed, M. Slivinski, and K. D. Zimmer 
cared for experimental ducks and provided extensive logistical support. The Environmental Protection Agency, Mid-Continent Ecology Division, Duluth, Minnesota, provided partial support for analysis and manuscript preparation. J. E. Austin, G. A. Baldassarre, R. T. Eberhardt, D. W. Howerter, R. E. Kirby, S. J. Maxson, D. P. Rave, M. R. Riggs, R. F. Rockwell, L. C. M. Ross, J. J. Rotella, T. L. Shaffer, M. C. Zicus, and 2 anonymous reviewers commented on earlier drafts of the manuscript.

\section{LITERATURE CITED}

Afton, A. D., AND C. D. ANKNEy. 1991. Nutrientreserve dynamics of breeding lesser scaup: a test of competing hypotheses. Condor 93:89-97.

ANKNEY, C. D., AND A. D. AFTON. 1988. Bioenergetics of breeding northern shovelers: diet, nutrient reserves, clutch size, and incubation. Condor 90:459-472.

Bellrose, F. C. 1976. Ducks, geese and swans of North America. Stackpole Books, Harrisburg, Pennsylvania, USA.

BENGTSON, S. 1972. Reproduction and fluctuations in the size of duck populations at Lake Mývatn, Iceland. Oikos 23:35-58.

Bieler, G. S., AND R. L. Williams. 1995. Cluster sampling techniques in quantal response teratology and developmental toxicity studies. Biometrics 51:764-776.

Brinkman, M. A., AND W. G. Duffy. 1996. Evaluation of four wetland aquatic invertebrate samplers and four sample sorting methods. Journal of Freshwater Ecology 11:193-200.

Brown, P. W., AND M. L. HunTER, JR. 1984/85. Potential effects of insecticides on the survival of dabbling duck broods. Journal of the Minnesota Academy of Science 50:41-45.

Chura, N. J. 1961. Food availability and preferences of juvenile mallards. Transactions of the North American Wildlife and Natural Resources Conference 26:121-134.

Cowardin, L. M., D. S. Gilmer, And C. W. ShaifFER. 1985. Mallard recruitment in the agricultural environment of North Dakota. Wildlife Monographs 92.

DANELl, K., AND K. SJÖBERG. 1982. Seasonal and diel changes in the feeding behaviour of some dabbling duck species on a breeding lake in northern Sweden. Ornis Scandinavica 13:129 134.

DunCAN, D. C. 1988. Body reserves of neonate northern pintails (Anas acuta). Canadian Journal of Zoology 66:811-816.

Euliss, N. H., JR., ANd G. Grodhaus. 1987. Management of midges and other invertebrates for waterfowl wintering in California. California Fish and Game 73:238-243.

Gibson, N. H. E. 1945. On the mating swarms of certain Chironomidae (Diptera). Transactions of the Royal Entomological Society of London 95: 263-294.

Giles, N. 1994. Tufted duck (Aythya fuligula) hab- itat use and brood survival increases after fish removal from gravel pit lakes. Hydrobiologia 279/ 280:387-392.

Hanson, M. A., AND M. R. Riggs. 1995. Potential effects of fish predation on wetland invertebrates: a comparison of wetlands with and without fathead minnows. Wetlands 15:167-175.

, C. RoY, AND K. ZiMMER. 1995. Bait fish effects on wetland invertebrate communities and mallard ducklings-preliminary results and conclusions. Pages 167-196 in B. Joselyn, editor. Summaries of wildlife research findings 1995. Minnesota Department of Natural Resources, Section of Wildlife, St. Paul, Minnesota, USA.

Held, J. W., AND J. J. Peterka. 1974. Age, growth, and food habits of the fathead minnow (Pimephales promelas) in saline lakes. Transactions of the American Fisheries Society 103:743-756.

Hill, D., R. WRIGHT, AND M. STREET. 1987. Survival of mallard ducklings Anas platyrhynchos and competition with fish for invertebrates on a flooded gravel quarry in England. Ibis 129:159 167.

Hosmer, D. W., JR., AND S. Lemeshow. 1989. Applied logistic regression. John Wiley \& Sons, New York, New York, USA.

Hunter, M. L., JR., J. W. Witham, and H. Dow. 1984. Effects of carbaryl-induced depression in invertebrate abundance on the growth and behavior of American black duck and mallard ducklings. Canadian Journal of Zoology 62:452-456.

JOHNSON, D. H., J. D. NiCHOLS, AND M. D. SCHWARTZ. 1992. Population dynamics of breeding waterfowl. Pages 446-485 in B. D. J. Batt, A. D. Afton, M. G. Anderson, C. D. Ankney, D. H. Johnson, J. A. Kadlec, and G. L. Krapu, editors. Ecology and management of breeding waterfowl. University of Minnesota Press, Minneapolis, Minnesota, USA.

, D. W. Sparling, and L. M. Cowardin. 1987. A model of the productivity of the mallard duck. Ecological Modelling 38:257-275.

KAPlan, E. L., AND P. MEIER. 1958. Nonparametric estimation from incomplete observations. Journal of the American Statistical Association 53:457481.

KEAR, J. 1965. The internal food reserves of hatching mallard ducklings. Journal of Wildlife Management 29:523-528.

Korschgen, C. E., K. P. Kenow, W. L. Green, D. H. Johnson, M. D. Samuel, and L. Sileo. 1996. Survival of radiomarked canvasback ducklings in northwestern Minnesota. Journal of Wildlife Management 60:120-132.

KrAPU, G. L. 1974. Feeding ecology of pintail hens during reproduction. Auk 91:278-290.

KURECK, A. 1979. Two circadian eclosion times in Chironomus thummi (Diptera), alternately selected with different temperatures. Oecologia 40: 311-323.

LOKEMOEN, J. T., D. H. JohnSon, AND D. E. SharP. 1990. Weights of wild mallard Anas platyrhynchos, gadwall $A$. strepera, and blue-winged teal A. discors during the breeding season. Wildfowl 41:122-130.

MCCARTHY, W. F. 1995. Direct and indirect effects 
of esfenvalerate on wetland biota. Thesis, University of Minnesota, Minneapolis, Minnesota, USA.

ORTHMEYER, D. L., AND I. J. BALL. 1990. Survival of mallard broods on Benton Lake National Wildlife Refuge in northcentral Montana. Journal of Wildlife Management 54:62-66.

Pehrsson, O., AND K. G. K. NYSTRÖM. 1988. Growth and movements of oldsquaw ducklings in relation to food. Journal of Wildlife Management 52:185-191.

Perret, N. G. 1962. The spring and summer foods of the common mallard (Anas platyrhynchos platyrhynchos L.) in south central Manitoba. Thesis, University of British Columbia, Vancouver, British Columbia, Canada.

RHYMER, J. M. 1982. Effect of egg weight and renesting on thermoregulatory ability and growth of mallard ducklings. Thesis, University of Manitoba, Winnipeg, Manitoba, Canada.

RICHARDS, F. J. 1959. A flexible growth function for empirical use. Journal of Experimental Botany 10:290-300

Rotella, J. J., AND J. T. RATTI. 1992. Mallard brood survival and wetland habitat conditions in southwestern Manitoba. Journal of Wildlife Management 56:499-507.

Roy, C. C. 1995. Impact of fathead minnows on invertebrate communities and mallard ducklings in experimental wetlands. Thesis, North Dakota State University, Fargo, North Dakota, USA.

Sargeant, A. B., G. A. Swanson, AND H. A. Doty. 1973. Selective predation by mink, Mustela vison, on waterfowl. American Midland Naturalist 89:208-214.

SAS INSTITUTE. 1990. SAS/STAT user's guide. Version 6. SAS Institute, Cary, North Carolina, USA.

1996. SAS/STAT software: changes and enhancements through release 6.11. SAS Institute, Cary, North Carolina, USA.

SEDINGER, J. S. 1992. Ecology of prefledging waterfowl. Pages 109-127 in B. D. J. Batt, A. D. Afton, M. G. Anderson, C. D. Ankney, D. H. Johnson, J. A. Kadlec, and G. L. Krapu, editors. Ecology and management of breeding waterfowl. University of Minnesota Press, Minneapolis, Minnesota, USA.

ShaH, B. V., B. G. Barnwell, AND G. S. Bieler. 1996. SUDAAN user's manual, release 7.0. Research Triangle Institute, Research Triangle Park, North Carolina, USA.

Stewart, R. E., AND H. A. Kantrud. 1971. Classification of natural ponds and lakes in the glaci- ated prairie region. U.S. Fish and Wildlife Service Resource Publication 92.

STREET, M. 1977. The food of mallard ducklings in a wet gravel quarry, and its relation to duckling survival. Wildfowl 28:113-125.

1978. The role of insects in the diet of mallard ducklings - an experimental approach. Wildfowl 29:93-100.

SUGDEN, L. G. 1973. Feeding ecology of pintail, gadwall, American widgeon, and lesser scaup ducklings. Canadian Wildlife Service Report Series 24. - E. A. DRIVER, AND M. C. S. KingSLey. 1981. Growth and energy consumption by captive mallards. Canadian Journal of Zoology 59: $1567-1570$

Swanson, G. A. 1977. Diel food selection by Anatinae on a waste-stabilization system. Journal of Wildlife Management 41:226-231.

1978. Funnel trap for collecting littoral aquatic invertebrates. Progressive Fish-Culturist 40:73.

, AND H. F. Duebbert. 1989. Wetland habitats of waterfowl in the Prairie Pothole Region. Pages 228-267 in A. Van Der Valk, editor. Northern prairie wetlands. Iowa State University Press, Ames, Iowa, USA.

- AND A. B. SARGEANT. 1972. Observation of nighttime feeding behavior of ducks. Journal of Wildlife Management 36:959-961.

SWENNEN, C. 1989. Gull predation upon eider Somateria mollissima ducklings: destruction or elimination of the unfit? Ardea 77:21-45.

SYRJÄMÄKI, J. 1964. Swarming and mating behaviour of Allochironomus crassiforceps Kieff. (Dipt. Chironomidae). Annales Zoologici Fennici 1:125145.

Talent, L. G., R. L. Jarvis, AND G. L. Krapu. 1983. Survival of mallard broods in south-central North Dakota. Condor 85:74-78.

, G. L. KRAPU, AND R. L. JaRvis. 1982. Habitat use by mallard broods in south central North Dakota. Journal of Wildlife Management 46:629 635.

TrotTIER, R. 1973. Influence of temperature and humidity on the emergence behaviour of Anax junius (Odonata: Aeshnidae). Canadian Entomologist 105:975-984.

WILliams, C. B. 1961. Studies in the effect of weather conditions on the activity and abundance of insect populations. Philosophical Transactions of the Royal Society of London Series B 244:331378.

Received 27 January 1997.

Accepted 16 May 1997.

Associate Editor: Rockwell. 